\title{
Kademeli Lif Takviyeli Kompozit Beton Kirişlerin Eğilme Davranışı
}

\author{
Abdullah Müsevitoğlu ${ }^{*}$, Atilla Özütok ${ }^{2}$, Serkan Salkım³, Oğuzhan Çağlar ${ }^{4}$, Gökalp Kırca ${ }^{5}$, Kadirhan Ertürk ${ }^{6}$, \\ Mesut Acar ${ }^{7}$ \\ 1* KTO Karatay Üniversitesi, Mühendislik ve Doğa Bilimleri Fakültesi, İnşaat Mühendisliği Bölümü, Konya, Türkiye, (ORCID: 0000-0002-0293-3424), \\ abdullah.musevitoglu@karatay.edu.tr \\ ${ }^{2}$ KTO Karatay Üniversitesi, Mühendislik ve Doğa Bilimleri Fakültesi, İnşaat Mühendisliği Bölümü, Konya, Türkiye (ORCID: 0000-0002-9000-283X), \\ atilla.ozutok@karatay.edu.tr \\ ${ }^{3}$ KTO Karatay Üniversitesi, Mühendislik ve Doğa Bilimleri Fakültesi, İnşaat Mühendisliği Bölümü, Konya, Türkiye (ORCID: 0000-0002-0930-687X), \\ salkimserkann@gmail.com \\ ${ }^{4}$ KTO Karatay Üniversitesi, Mühendislik ve Doğa Bilimleri Fakültesi, İnşaat Mühendisliği Bölümü, Konya, Türkiye (ORCID: 0000-0003-4486-5076), \\ caglarr.oguzhan@gmail.com \\ 5 KTO Karatay Üniversitesi, Mühendislik ve Doğa Bilimleri Fakültesi, İş̧aat Mühendisliği Bölümü, Konya, Türkiye (ORCID: 0000-0002-5475-4815), \\ krcgokalp@gmail.com \\ ${ }^{6}$ KTO Karatay Üniversitesi, Mühendislik ve Doğa Bilimleri Fakültesi, İsşaat Mühendisliği Bölümü, Konya, Türkiye (ORCID: 0000-0002-9637-1302), \\ erturkkdrhn@gmail.com \\ ${ }^{7}$ KTO Karatay Üniversitesi, Mühendislik ve Doğa Bilimleri Fakültesi, İsşaat Mühendisliği Bölümü, Konya, Türkiye (ORCID: 0000-0001-7224-3595), \\ thmesutacar1@gmail.com
}

(1st International Conference on Applied Engineering and Natural Sciences ICAENS 2021, November 1-3, 2021)

(DOI: $10.31590 /$ ejosat.999026)

ATIF/REFERENCE: Müsevitoğlu, A., Özütok, A., Salkım, S., Çağlar, O., Kırca, G., Ertürk, K., \& Acar, M. (2021). Lif takviyelinormal beton kompozit kirişlerin eğilme davranışı. Avrupa Bilim ve Teknoloji Dergisi, (28), 338-345.

\section{$\ddot{\mathbf{O z}}$}

Bu çalışmada kademeli lif takviyeli kompozit kirişlerin eğilme dayanımları araştırılmıştır. Beton hacmine oranla \%2 oranında lif (çelik ve makro sentetik polipropilen lif/MS) takviyeli karışımlar hazırlanmıştır. Katmanın konumuna (alt, üst ve tamamı) göre farklı özelliklerde hazırlanan 7 adet yarım ölçekli kiriş üzerinde 4 noktalı eğilme testi yapılmıştır. Deneyler sonrası numunelerde yükdeplasman davranışı, enerji yutma kapasitesi, çatlak ilerleyişi ve göçme durumları incelenmiştir. Yük taşıma kapasitelerinde referans kirişlere kıyasla, tamamı MS lif takviyeli olan kirişlerde \%30, çelik lif takviyeli betonun alt katmanda olduğu kirişlerde \%27 artış görülmüştür. MS lif takviyeli kirişlerde yük taşıma kapasiteleri maksimuma ulaştıktan sonra yük altında deplasman yapabilme kabiliyeti çelik lif içeren kirişlere göre daha fazla çıkmaktadır. Enerji yutma kapasiteleri incelendiğinde lif takviyeli betonun (FRC) alt katmanda olduğu kirişlerin, üst katmanda bulunan kirişlere oranla daha sünek davranış gözlenmiştir. FRC tabakasının kirişin üst kısmında olduğu durumlarda maksimum yük taşıma kapasitesine ulaşıldıktan sonra normal beton (NC) tabakasında erken göçme gözlendiğinden ani yük kayıpları gözlenmiştir. Çalışma sonucunda fiber miktarının azaltılmasının fiber kullanımının yaygın olduğu yapıların maliyetlerine olumlu yönde katkı sağlayacağı düşünülmektedir.

Anahtar Kelimeler: Fiber takviyeli beton, Makro sentetik polipropilen fiber, çelik fiber, eğilme dayanımı, Kompozit.

\section{Flexural Behavior of Graded Fiber Reinforced Composite Concrete Beams}

\begin{abstract}
In this study, the flexural strengths of graded fiber-reinforced composite beams were investigated. Mixtures reinforced with fiber (steel and macro-synthetic polypropylene fiber/MS) at a ratio of $2 \%$ to the concrete volume were prepared. A 4-point bending test was performed on 7 half-scale beams prepared according to the position of the layer (bottom, top and whole). After the tests, loaddisplacement behavior, energy absorption capacity, crack propagation, and failure mechanism of the specimens were investigated. Compared to the reference beams, the load-carrying capacities increased by $30 \%$ in beams with full MS fiber reinforcement and by $27 \%$ in beams with steel fiber reinforced concrete in the substrate. After the load-carrying capacity of MS fiber-reinforced beams reaches the maximum, the ability to make displacement under load is higher than the beams containing steel fiber. When the energy absorption capacities are examined, it can be said that the beams with fiber reinforced concrete (FRC) in the bottom layer behave more ductility than the beams in the upper layer. In cases where the FRC layer is at the top of the beam, sudden load losses are observed as early failure is observed in the normal concrete (NC) layer after the maximum load-carrying capacity is reached. As a result of the study, it is thought that reducing the amount of fiber will contribute positively to the costs of structures where fiber use is common.
\end{abstract}

Keywords: Fiber reinforced concrete, Macro synthetic polypropylene fiber, Steel fiber, Flexural behavior, Composite.

* Sorumlu Yazar: abdullah.musevitoglu@karatay.edu.tr 


\section{Giriş}

Beton düşük çekme mukavemetine sahip gevrek bir malzemedir. $\mathrm{Bu}$ özellikler betona lif ilave edilmesi ile iyileştirilebilmektedir. Lif takviyeli beton (FRC), çimento esaslı bir matrise ve süreksiz bir donatı olan fibere sahip kompozit bir malzemedir (Mudadu et al., 2018). FRC, tünel işlerinde, demiryollarında, barajlarda ve prekast elemanlar gibi yapılarda yaygın olarak kullanılmaktadır. Cam, çelik, polipropilen ve karbon lifleri, kullanım amaçlarına göre belirlenen oranlarda karıştırılarak betona uygulanır ve böylece beton karışımına farklı özellikler kazandırılmaktadır (Hsie et al., 2008; Yao et al., 2003). Betona lif eklenmesi, çatlak direncini, sünekliği, enerji yutma kapasitesini ve mukavemetini geliştirmektedir (Yin et al., 2015). Beton karışımındaki lifler, doğru oranlarda kullanıldığında ve dağıtıldığında betonun dayanıklılığını arttırmakta ve çatlakların ilerleyişini yavaşlatmaktadır (Pujadas et al., 2017). Bu makale kapsamında lif olarak makro sentetik polipropilen (MS) ve çelik lifler incelenmiştir. Birçok çalışma FRC'nin mekanik ve fiziksel özelliklerine odaklanmıştır. Betonda MS liflerinin kullanımının, kirişlerde yük taşıma kapasitesini ve kırılma enerjisini arttırdığ (Buratti et al., 2011; Chiranjeevi Reddy \& Subramaniam, 2017; Oh et al., 2007), sünekliğini, kesme mukavemetini ve kırılmaya karş1 direnci iyileştirdiği (Altoubat et al., 2009; Hasan et al., 2011) görülmüştür. Geri dönüştürülmüş agrega ile üretilmiş beton karışımlarına MS liflerin eklenmesi betonun kırılma enerjisini ve tokluğunu önemli ölçüde artırmıştır; aynı zamanda eğilme mukavemetini, sünekliğini, enerji yutma kapasitesini (Kazmi et al., 2018) ve gerilme-şekil değiştirme davranışını (Kazmi et al., 2019) geliştirmiştir. Ayrıca MS lif takviyesi betonun birim hacim ağırlığını önemli ölçüde değiştirmemiş, karbonatlaşma derinliğini arttırmamış ve su emme miktarını azaltmamıştır (Bolat et al., 2014). Betona çelik lif eklenmesi, sünekliğini, eğilme mukavemetini, sertlik gibi betonun mekanik özelliklerini geliştirmektedir (Abbass et al., 2018; Biolzi \& Cattaneo, 2017; Ding et al., 2019; Hu \& Wu, 2018). Ek olarak çelik lif ilavesi nihai çatlak genişliğini attırmaktadır (Mudadu et al., 2018). Yüksek mukavemetli betonlarda çelik lif uygulaması kırılma enerjisini (Kazemi et al., 2017), basınç dayanımını, yarmada çekme mukavemetini ve tokluğunu arttırmıştır (Song \& Hwang, 2004).
Çelik lif ilavesi ultra yüksek performanslı betonlarda basınç dayanımını ve yarmada çekme dayanımı özelliklerini arttırmaktadır (Smarzewski \& Barnat-Hunek, 2018). Kendiliğinden yerleşen betonlarda çelik lif kullanılması çekme mukavemetini iyileştirerek sünekliliği arttırmaktadır (de Alencar Monteiro et al., 2018; Sucharda et al., 2017). Geri dönüştürülebilen agregalı betonlarda çelik lif ilavesi, kesme davranışını (Chaboki et al., 2019), yük taşıma kapasitesini, çekme mukavemetini iyileştirirken çatlamayı azaltmaktadır (Chaboki et al., 2018).

Betona fiber ilavesi betonun maliyetini önemli ölçüde arttırmaktadır. Bu sorun fiberin beton içerisinde kullanılması ile ilgili yapılan uygulamaları kısıtlamaktadır. Kirişlerde fiber miktarının azaltılması, inşaat maliyetlerini azaltırken aynı zamanda kirişlerin normal betona göre daha iyi eğilme davranışı sergilemesini sağlayacaktır. Hem normal beton (NC) hem de FRC'nin içeren kompozit kirişler ile ilgili raporlar mevcuttur (Hussein \& Amleh, 2015; Martinola et al., 2010; Nguyen et al., 2021; Tong et al., 2021). FRC kirişlerin sahip olduğu özelliklerin birçoğu bilinmesine rağmen kompozit kirişlerin davranışları hakkında yapılan çalışmalar sınırlıdır. $\mathrm{Bu}$ çalışmada fiber kullanımını azaltarak hem ekonomik hem de yeterli eğilme dayanımına sahip kiriş üretilmesi amaçlanmıştır. Çalışmada FRCNC kompozit kirişlerinin eğilme etkisi altında davranışı incelenmiştir. Bu kapsamda bir tanesi referans olmak üzere 7 adet farklı özelliklere sahip yarım ölçekli kiriş monotonik artan yükleme altında 4 noktalı eğilme testine tabi tutulmuştur.

\section{Materyal ve Metot}

7 adet farklı özelliklere sahip kiriş eğilme davranışlarını incelemek için KTO Karatay Üniversitesi Yap1 Mekaniği Laboratuvarında üretilmiştir. Test kirişleri, FRC'nin konumuna ve fiberin türüne göre hazırlanmıştır. Kirişler $1500 \mathrm{~mm}$ uzunluğunda, $150 \mathrm{~mm}$ x $300 \mathrm{~mm}$ kesitinde hazırlanmıştır. Kirişlerin özellikleri ve detayları Şekil 1'de verilmiştir. Beton karışımları, betonda kullanılan lif tipine göre çelik lif ise SFRC, MS lif ise PFRC ve lif içermeyen kiriş ise $\mathrm{NC}$ olarak isimlendirilmiştir.

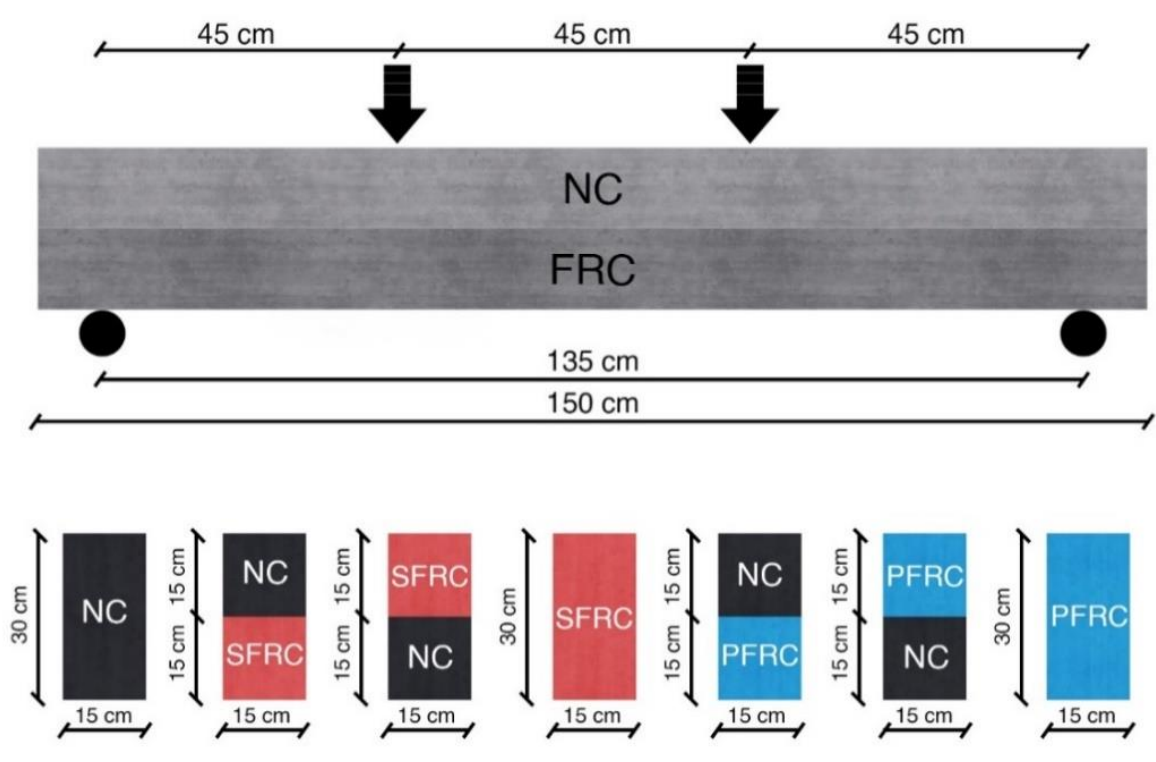

Şekil 1. Kiriş özellikleri ve detayları 


\subsection{Malzeme Özellikleri}

Beton karışımında bağlayıcı olarak BS EN 197-1 (BS EN 197-1, 2011) standatına uygun, özgül ağırlığı 3,15 g/ $\mathrm{cm}^{3}$, özgül yüzey alanı (Blaine) $3500-3700 \mathrm{~cm}^{2} / \mathrm{gr}$ olan portland çimentosu (CEM II 42,5R) ve maksimum çap1 22,4 $\mathrm{mm}$ olan agrega kullanılmıştır. Betonların işlenebilirliğini arttırmak amacıyla bağlayıcı miktarının \%0,5'i oranında super akışkanlaştırıcı katkı malzemesi kullanılmıştır. Farklı özelliklere sahip iki tip fiber (MS ve çelik) beton karışımında kullanılmıştır (Şekil 2). Çalışmada kullanılan fiberler ASTM C 1116 (ASTM C 1116, 2015) standartına göre üretilmiş ve Tablo 1 'de özellikleri verilmiştir. Çalışmada C30 beton üretilmesi amaçlanmıştır. Tüm beton karışımlarında kullanılan malzemelerin detayları Tablo 2'de verilmiştir.

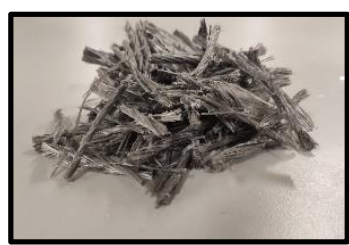

a) Makro sentetik polipropilen lif

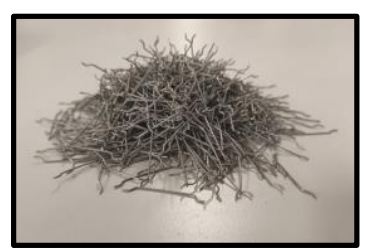

b) Çelik lif
Şekil 2. Deneysel çalışmada kullanılan lifler

Tablo 1. Makro sentetik polipropilen lif ve çelik lifin özellikleri

\begin{tabular}{cccccc}
\hline Fiber Tipi & $\begin{array}{c}\text { Uzunluk } \\
\mathbf{l}(\mathbf{m m})\end{array}$ & $\begin{array}{c}\text { Çap } \\
\mathbf{d}(\mathbf{m m})\end{array}$ & $\begin{array}{c}\text { En/boy oranı } \\
(\mathbf{l} / \mathbf{d})\end{array}$ & $\begin{array}{c}\text { Yoğunluk } \\
\left(\mathbf{k g} / \mathbf{m}^{\mathbf{3}}\right)\end{array}$ & $\begin{array}{c}\text { Çekme Dayanımı } \\
\left(\mathbf{N} / \mathbf{m m}^{\mathbf{2}}\right)\end{array}$ \\
\hline MS & 54 & 0.65 & 83 & 0.91 & $550-750$ \\
\hline Çelik & 35 & 0.70 & 50 & 7.85 & 1400 \\
\hline
\end{tabular}

Tablo 2. Beton karışımda kullanılan malzeme detayları

\begin{tabular}{lccc}
\hline \multicolumn{1}{c}{ Karışım } & NC & PFRC & SFRC \\
\hline Çimento (kg/m3) & 350.0 & 350.0 & 350.0 \\
\hline Kum $(\mathrm{kg} / \mathbf{m 3})$ & 900.0 & 900.0 & 900.0 \\
\hline Agrega (kg/m3) & 900.0 & 900.0 & 900.0 \\
\hline MS Lif (\%) & - & 2.0 & - \\
\hline Çelik lif (\%) & - & - & 2.0 \\
\hline Akışkanlaştırıcı (\%) & 0.5 & 0.5 & 0.5 \\
\hline Su $(\mathbf{k g / m 3 )}$ & 189.1 & 189.1 & 189.1 \\
\hline S/Ç & 0.54 & 0.54 & 0.54 \\
\hline
\end{tabular}

\subsection{Betonun mekanik özellikleri}

NC, PFRC ve SFRC betonun basınç dayanımları, 150x150x150 mm boyutlarında küp numunelerin basınç testiyle elde edilmiştir. Çekme dayanımları ise 150 x $300 \mathrm{~mm}$ boyutlarında silindir numuneler üzerinde yapılan yarmada çekme dayanım testi ile elde edilmiştir. Küp ve silindir numuneler, test kirişleri ile aynı gün en az 6 adet olmak üzere dökülmüştür. Dökümden sonra küp ve silindir NC, PFRC ve SFRC numuneleri 28 gün boyunca suda kürlenmiştir. Tablo 3 'te tüm numunelerin 7 ve 28 günlük ortalama basınç ve yarmada çekme dayanımları verilmiştir.

Tablo 3. Beton basınç ve yarmada çekme dayanımları

\begin{tabular}{cccccc}
\hline \multirow{2}{*}{ Fiber Tipi } & \multirow{2}{*}{$\begin{array}{c}\text { Numune } \\
\text { gösterimi }\end{array}$} & \multicolumn{2}{c}{$\begin{array}{c}\text { Basıç Dayanımı } \\
\text { (MPa) }\end{array}$} & \multicolumn{2}{c}{ Yarmada Çekme Dayanımı } \\
\cline { 3 - 6 } & & $\mathbf{7}$ gün & $\mathbf{2 8}$ gün & $\mathbf{7}$ gün & $\mathbf{2 8}$ gün \\
\hline NC & 32.05 & 35.78 & 2.05 & 2.49 \\
\hline SFRC & & 33.68 & 34.72 & 3.44 & 3.93 \\
\hline \multirow{2}{*}{ PFRC } & & 33.36 & 34.51 & 2.99 & 3.88 \\
\hline
\end{tabular}

Tablo 3'te görüldüğü üzere beton hacminin \%2'si oranında çelik ve MS lif katkısının betonun basınç dayanımına etkisi sınırlı kalmaktadır. Tüm FRC numununeleri düz beton numunelerine kıyasla eksenel yükleme altında daha sünek bir kırılma modu sergilemiştir. FRC küp numuneleri tamamen ezilmemiştir ve bütünlüğünü korumuştur. Yarmada çekme dayanımlarında NC betona göre sırasıyla çelik lif katkılı betonlarda \%58, MS lif katkılı betonlarda \%56 oranında artış görülmüştür. Yarmada çekme dayanımları 2P/ $\pi$ DL denklemi kullanılarak hesaplanmıştır. Burada P kırılma yükünü, D çapı, L ise uzunluğu temsil etmektedir. Normal beton numunelerinde tek bir dikey çatlak oluşumu gözlenirken, FRC numunelerinde ise göçme düzlemi boyunca oluşan gerilmeler nedeniyle daha sünek kırılma görülmüştür.

\subsection{Test numunelerinin hazırlanması}

Teste tabi tutulacak kirişlerin dökümleri için ahşap kalıplar kullanılmıştır. Kalıptan ayrılmanın kolay olması için kalıp iç yüzeyleri yağlanmıştır. Beton karışımındaki malzemelerin karışımı için 60 litrelik hacme sahip laboratuvar mikseri kullanılmıştır. NC, PFRC ve SFRC betonların hazırlanması için aynı prosedür uygulanmıştır. İlk olarak yaklaşık 10 dakika çimento, ince agrega ve iri agrega içeren kuru bir karışım hazırlanmıştır. Sonrasında, karışıma su ilave edildi ve 10 dakika süre karıştırıldı, Daha sonra karışıma süper akışkanlaştırıcı ilave edilerek 5 dakika daha karıştırıldı. Son olarak lif içeren betonlar için lifler mikser içerisine dikkatli bir şekilde atılarak 5 dakika 
daha karıștırıldı. Ardından elde edilen karışım kalıplara yerleştirildi. İki kademeden oluşan kompozit kirişler kalıplara yerleştirilirken, alt kademenin yerleştirilme ve sıkıştırma aşamasından sonra 1 saat süreyle beklendikten sonra dikkatli bir şekilde üst tabakadaki beton yerleştirilip sıkıştırma işlemi tamamlanmıştır. Kiriş numuneleri 7 gün boyunca su kürüne tabi tutulmuştur. Laboatuvarda yapılan test numunelerinin hazırlanış aşamaları Şekil 3 'te verilmiştir.
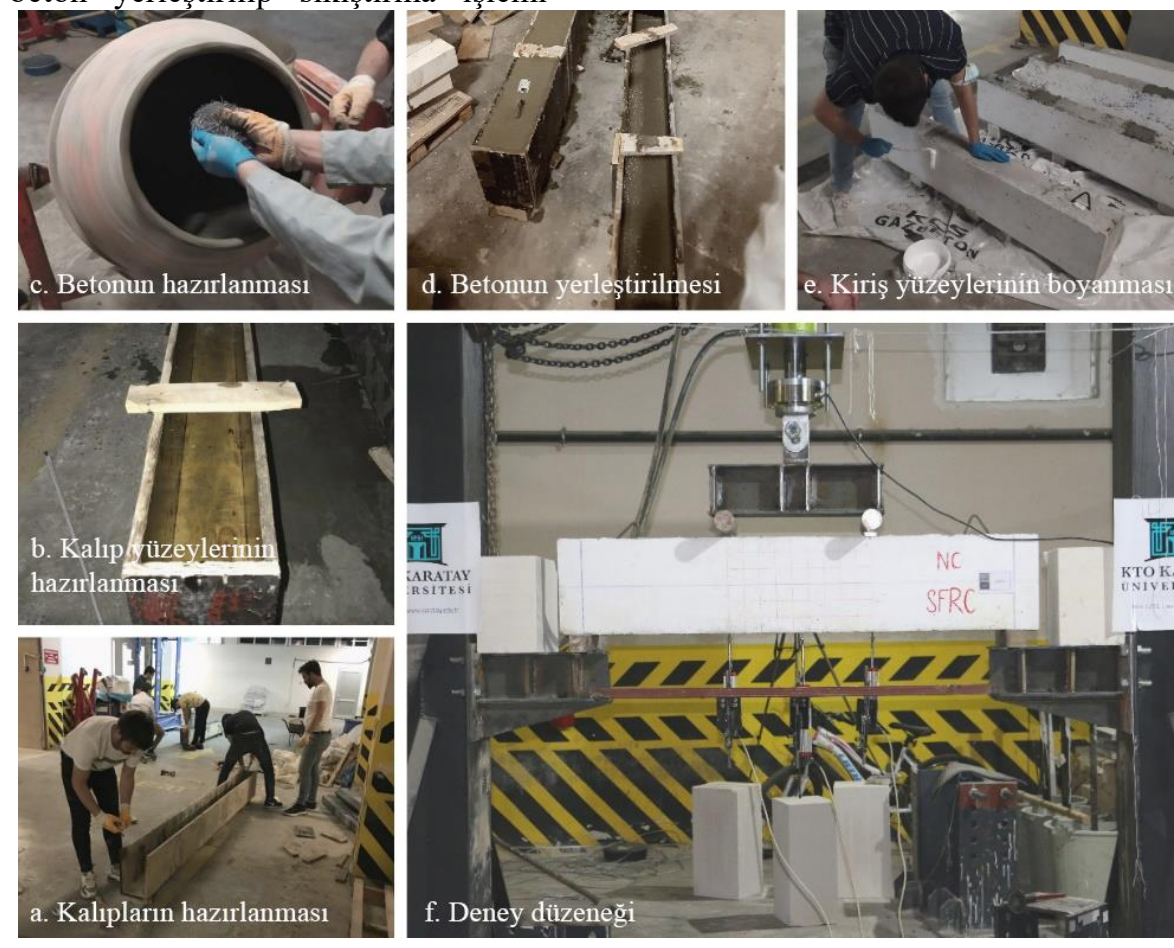

Şekil 3. Deney numunelerinin test için hazırlanması

\subsection{Deney düzeneği ve prosedürü}

Test kirişleri ilk 7 gün kürlenmiş ve 28 gün boyunca oda koşullarında tutulmuştur. Test kirişleri monotonik olarak artan bir yükleme ile 4 noktalı eğilme testine tabi tutulmuştur. Şekil 4 'te bu çalışmada kullanılan deney düzeneği verilmiştir. Yük altında oluşan deplasmanların ölçülmesi amacıyla 3 adet lineer potansiyometrik cetvel yerleştirilmiştir. Yükleme $300 \mathrm{kN}$ kapasiteli hidrolik kriko yardımıyla yapılmıştır. Destekler arası net mesafe $135 \mathrm{~cm}$ ve yükleme noktaları arası mesafe $45 \mathrm{~cm}$ 'dir. Deney esnasında oluşan yük ve deplasman değerleri $600 \mathrm{kN}$ kapasiteli yük ölçer tarafından ölçülmüştür. Test numuneleri, yük taşıma kapasitelerinde önemli bir azalış görülene kadar yüklenmiştir.

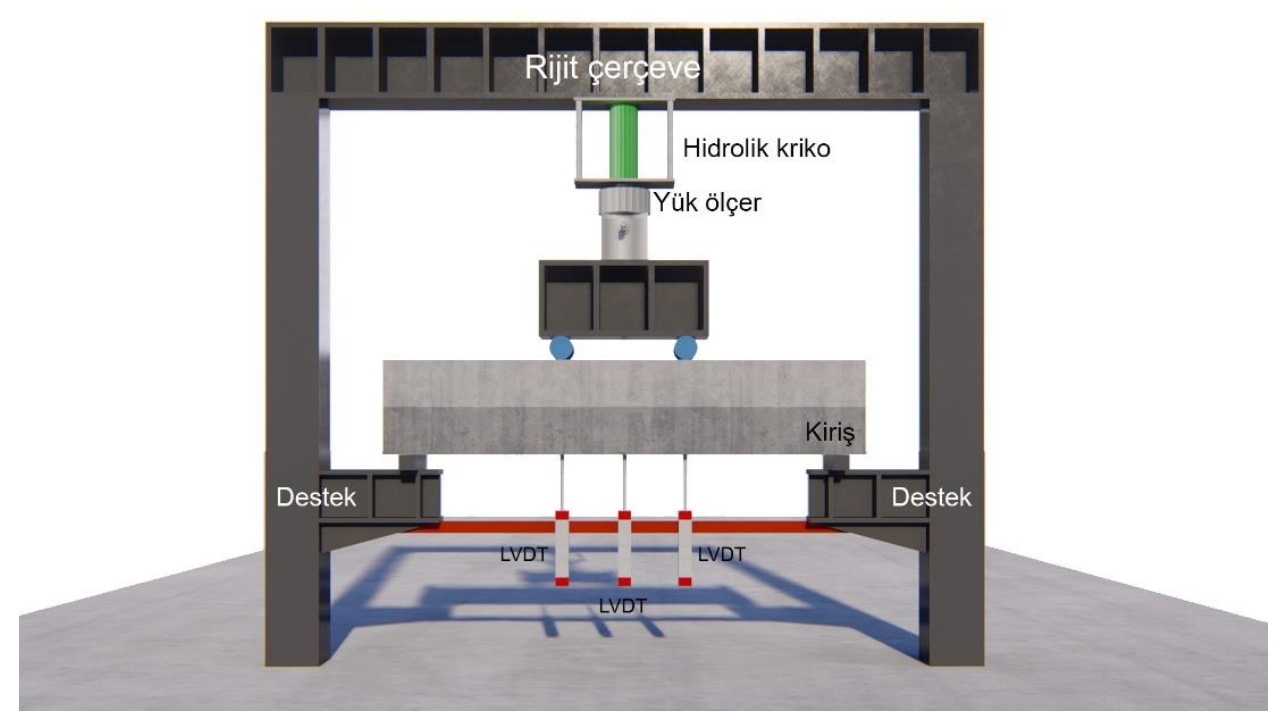

Şekil 4. Deney düzeneği 


\section{Araştırma Sonuçları ve Tartışma}

Lifli betonun konumuna ve lif tiplerine göre faklı özelliklerde hazırlanan 7 adet kiriş monotonik artan yükleme altında test edilmiştir. Deneyler sonrası ana araştırılan parametreler, yük yer değiştirme davranışı, enerji yutma kapasitesi, çatlak ilerleyişi, göçme mekanizmasıdır.

\subsection{Yük-deplasman davranışı}

Test numunelerinin yük altında yapmış olduğu deplasmanlar Şekil 5' de verilmiştir. NC kirişi maksimum yük taşıma kapasitesine ulaştıktan sonra ani kırılma gerçekleşmiştir. Şekil 5a incelendiğinde çelik lif katkısının yük taşıma kapasitesini bir miktar arttırdığı görülmüştür. Çelik lif katkılı betonun kirişin alt kısmında bulunması yük taşıma kapasitesini ve yük altında deplasman yapabilme kabiliyetini olumlu olarak etkilemiştir. SFRC-NC kirişinde yük taşıma kapasitesi maksimuma ulaştıktan sonra ani olarak \%15'lik bir düşüş yaptıktan sonra kiriş yük taşımaya devam etmiştir. $\mathrm{Bu}$ da alt kısımda bulunan NC'nin tamamen işlevini kaybettiğini, sadece çelik lif içeren beton katmanının yük taşımaya devam ettiğini göstermektedir. SFRC ve SFRC-NC kirişlerinde ise bu durum gözükmemektedir. Şekil 5b incelendiğinde PFRC kirişinde maksimum yük taşıma kapasitesinin \%30 oranında arttığı görülmektedir. PFRC-NC ve NC-PFRC kirişlerinde ise yük taşıma kapasitesinde herhangi bir artış görülmemiştir. MS lif içeren her 3 kirişte, belli bir miktar yük

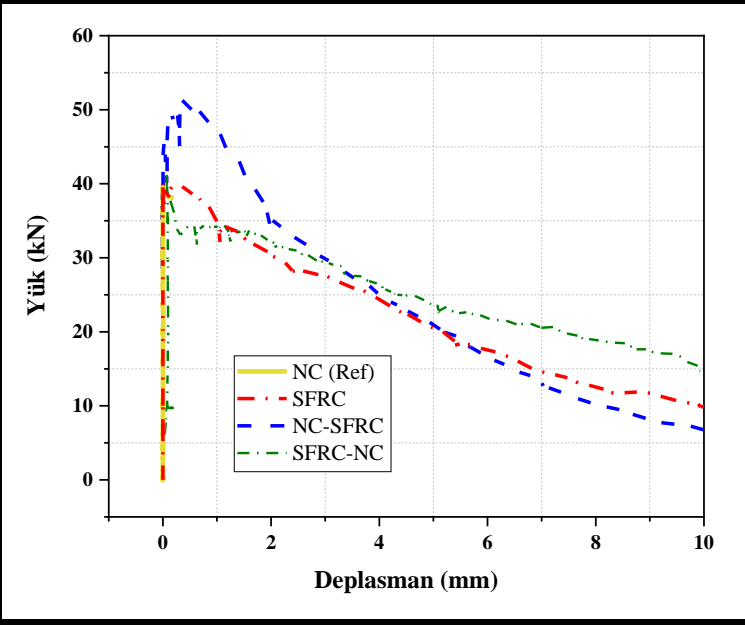

a) Çelik lif takviyeli kirişlerin yük-deplasman davranışı altında deplasman yapmaya devam etmektedir. Fakat PFRC-NC kirişinde yani PFRC tabakasının üst kısımda olduğu durumda kiriş maksimum yük taşıma kapasitesine ulaştıktan sonra ani bir kırılma davranışı göstererek yük taşıma kapasitesinin \%50'sini kaybetmiştir. Bu yük altında deplasman yapmaya devam etmiştir. NC-PFRC kirişi incelendiğinde ise maksimum yük altında belli bir miktar daha deplasman yaptıktan sonra lineer olarak yükte azalma görülmüştür. Hem çelik lif katkılı hem de MS lif katkılı kirişler incelendiğinde lifli beton tabakalarının üst kısımda olduğu durumlarda NC betonunun yetersizliğinden dolayı maksimum yük taşıma kapasitesine ulaştıktan sonra ani bir göçme oluştukmakta, dayanımının belli bir miktarını kaybederek sadece PRFC tabakası yük taşımaya devam etmektedir. Yük taşıma kapasitesi maksimuma ulaştıktan sonra PFRC içeren kirişlerde yük kaybı SFRC içeren kirişlere göre daha az oluşmaktadır. SFRC içeren kirişlerde yük taşıma kapasitesi maksimuma ulaştıktan sonra ani yük kayıpları görülmüştür. $\mathrm{Bu}$ durum MS lif katkılı kirişlerinin çelik lif katkılı kirişlere göre daha sünek davranış sergilediğini göstermektedir. Sonuç olarak yük-yer değiştirme grafikleri incelendiğinde lif katkılı olmayan NC kirişinde ani bir kırılma gerçekleşirken, lif katkılı olan kirişlerde daha sünek davranış gerçekleşmiştir. Eğilme açısından lif katkısının kirişin çekme bölgesinde yer almasının uygun olacağı bilinmektedir. NC-SFRC ve NC-PFRC kirişlerinde de görüldüğü gibi lifli tabakanın alt kısımda olması, üst kısımda olması durumuna göre daha iyi eğilme davranışı sergilemiştir.

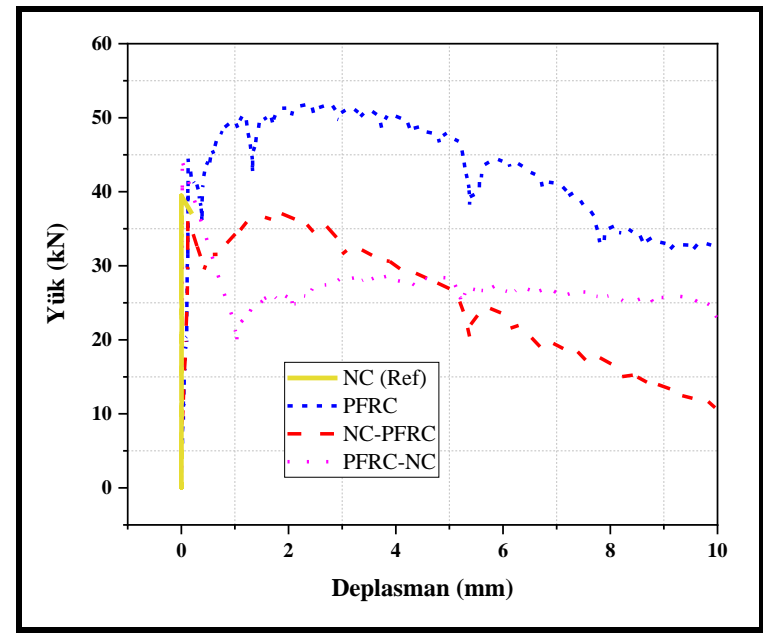

b) MS lif takviyeli kirişlerin yük-deplasman davranışı

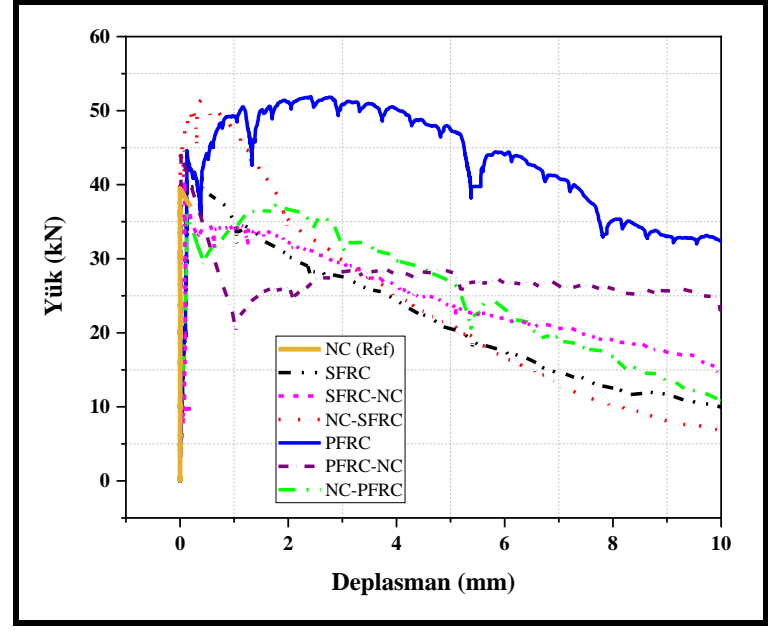

c) Tüm numunlerin yük-deplasman davranışı

Şekil 5. Test numunelerin yük-deplasman davranışı 


\subsection{Enerji yutma kapasitesi-süneklik}

Süneklik, kirişlerde oluşan deplasmanlardan ve enerji yutma kapasitesinden hesaplanmaktadır (Issa et al., 2011). Enerji yutma kapasitesi, yük-deplasman eğrisinde kiriş üzerindeki maksimum yükün \%85'ine karş1lık gelen sehim değerinin $\left(\delta_{\mathrm{u}}\right)$ sol kısmında kalan alan denklem 1 kullanılarak hesaplanmaktadır (Şekil 6).

$$
\int_{0}^{P} P d \delta
$$

Denklem 1 ve şekil 5 'te belirtilen parametreler: $\delta_{\mathrm{u}}$ deplasman değerleri, $\mathrm{P}$ and $\mathrm{P}_{\max }$ yük taşıma kapasitesidir.

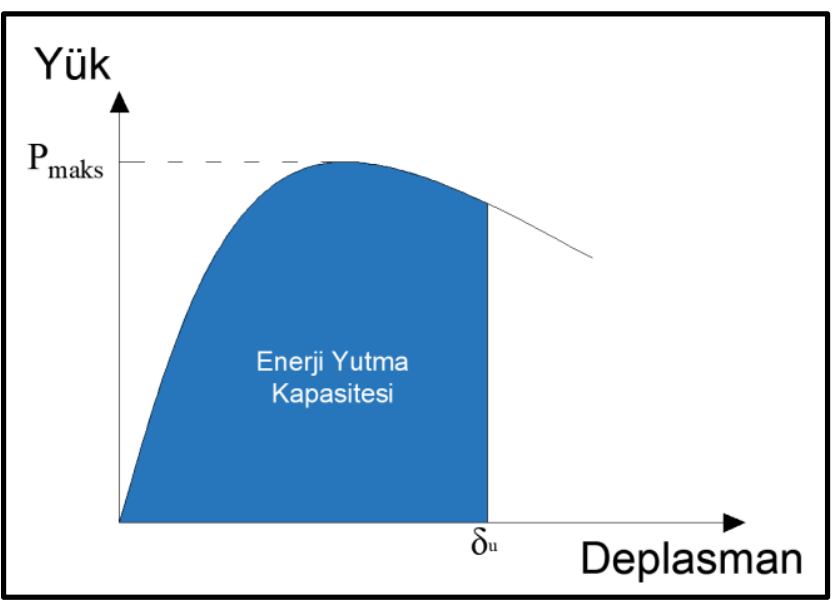

Şekil 6. Enerji yutma kapasitesi

Tablo 4. Test numuneleri enerji yutma kapasiteleri

\begin{tabular}{l|c}
\hline \multicolumn{1}{c|}{ Test numuneleri } & $\begin{array}{c}\text { Enerji Yutma } \\
\text { Kapasitesi (j) }\end{array}$ \\
\hline NC & - \\
\hline NC-SFRC & 63,94 \\
\hline SFRC-NC & 15,03 \\
\hline SFRC & 48,61 \\
\hline NC-SFRC & 132,04 \\
\hline PFRC-NC & 13,58 \\
\hline PFRC & 255,1 \\
\hline
\end{tabular}

Tablo 4' de kirişlerin enerji yutma kapasiteleri verilmiştir. NC kiriş maksimum yük taşıma kapasitesine ulaştığında göçme gözlendiği için dikkate alınmamıştır. Enerji yutma kapasitesinde SFRC tabakasının altta bulunduğu NC-SFRC kirişi SFRC tabakasının üstte bulunduğu kirişe kıyasla oldukça önemli bir artış görülmüştür. SFRC numunesinde ise daha erken göçme durumunun gözlenmesi fiberlerin homojen olarak karışmadığından kaynaklı olduğu düşünülmektedir. PFRC-NC kirişi maksimum yük taşıma kapasitesine ulaştığında altta bulunan NC tabakasının yetersizliğinden dolayı gerçekleşen ani yük kaybı sebebiyle enerji yutma kapasitesi NC-PFRC ve PFRC kirişlerine göre çok oldukça düşük çıkmıştır. PFRC, SFRC, NCSFRC, NC-PFRC kirişleri incelendiğinde PFRC içeren kirişler SFRC içeren kirişlere kıyasla daha yüksek enerji yutma kapasitesine ulaşmıştır. PFRC tabakası içeren kirişlerin maksimum yük taşıma kapasitesine ulaştıktan sonra yük kaybı olmadan deplasman yapma kabiliyetin daha yüksek olduğu görülmüştür. Aksine SFRC tabakası içeren kirişlerde maksimum yük taşıma kapasitesine ulaştıktan sonra yükün lineer olarak azaldığı görülmektedir. Buna bağlı olarak kirişlerde $\% 2$ oranında MS lif ilavesinin, çelik lif ilavesine göre daha sünek davranış sağladığı söylenebilir.

\section{3. Çatlak ilerleyişi ve göçme mekanizması}

Çalışmanın bu bölümünde liflerin ve lifli betonun bulunduğu katmanın konumunun kirişlerin davranışları üzerindeki etkisi analiz edildi ve referans numuneyle karşılaştırıldı. Kirişte makro çatlak oluşumunun mikro çatlak oluşumundan kaynaklandığı bilinmektedir. Lifler, mikro çatlakların oluşumunu geciktirerek kırılmanın gelişmesinde önemli bir etkiye sahiptir. Bu amaçla yapılan hasar analizinde çatlak oluşumları detaylı olarak incelenmiștir. Şekil 7'de tüm numunelerde oluşan çatlakların yüklere göre ilerleyişini ve göçme anındaki durumunu göstermektedir. Kirişte yükleme monotonik olarak artarak yapılmıştır. Ek olarak farklı renkler kullanılarak çatlakların ilerleyişi tespit edilmiştir. NC kirişinde de beklendiği gibi çatlak oluştuğu anda ani bir göçme gözlenmiştir. NC-SFRC kirişinde 40 $\mathrm{kN}$ yüke ulaşıldığında ilk eğilme çatlağı görülmüştür. Çatlak 50 $\mathrm{kN}$ yüke kadar ilerlemeye devam etmiştir. NC- PFRC kirişinde Üstte bulunan NC tabakasına eriştikten sonra çatlak yön değiştirerek ilerlemiştir. SFRC-NC ve PFRC-NC numunelerinde ise alt kısımda bulunan NC tabakasınından dolayı ilk çatlak oluşumu ani ve çatlak boyu daha uzun olarak gerçekleşmiştir. Bu iki numunede de 35-40 kN yük altında ilk eğilme çatlağı oluşmaya başlamış ve çatlak üst FRC katmanına kadar ilerlemiştir. Her iki numunede de kiriş maksimum yük taşıma kapasitesine ulaştıktan sonra ani yük kayıpları görülmüştür. PFRC ve SFRC kirişlerinde yaklașık olarak 35-40 kN yük altında ilk eğilme çatlakları oluşmuştur. PFRC içeren tüm kirişlerde çatlaklar SFRC içeren kirişlere göre daha yüksek yük taşıma kapasitelerinde oluştuğu görülmüştür. Kompozit kirişlerde herhangi bir ayrılma görülmemiştir. Bunun sebebi iki betonunun dökümü arasında kısa süre olması ve liflerin iki beton arasında ankraj görevi görmesi söylenebilir. 


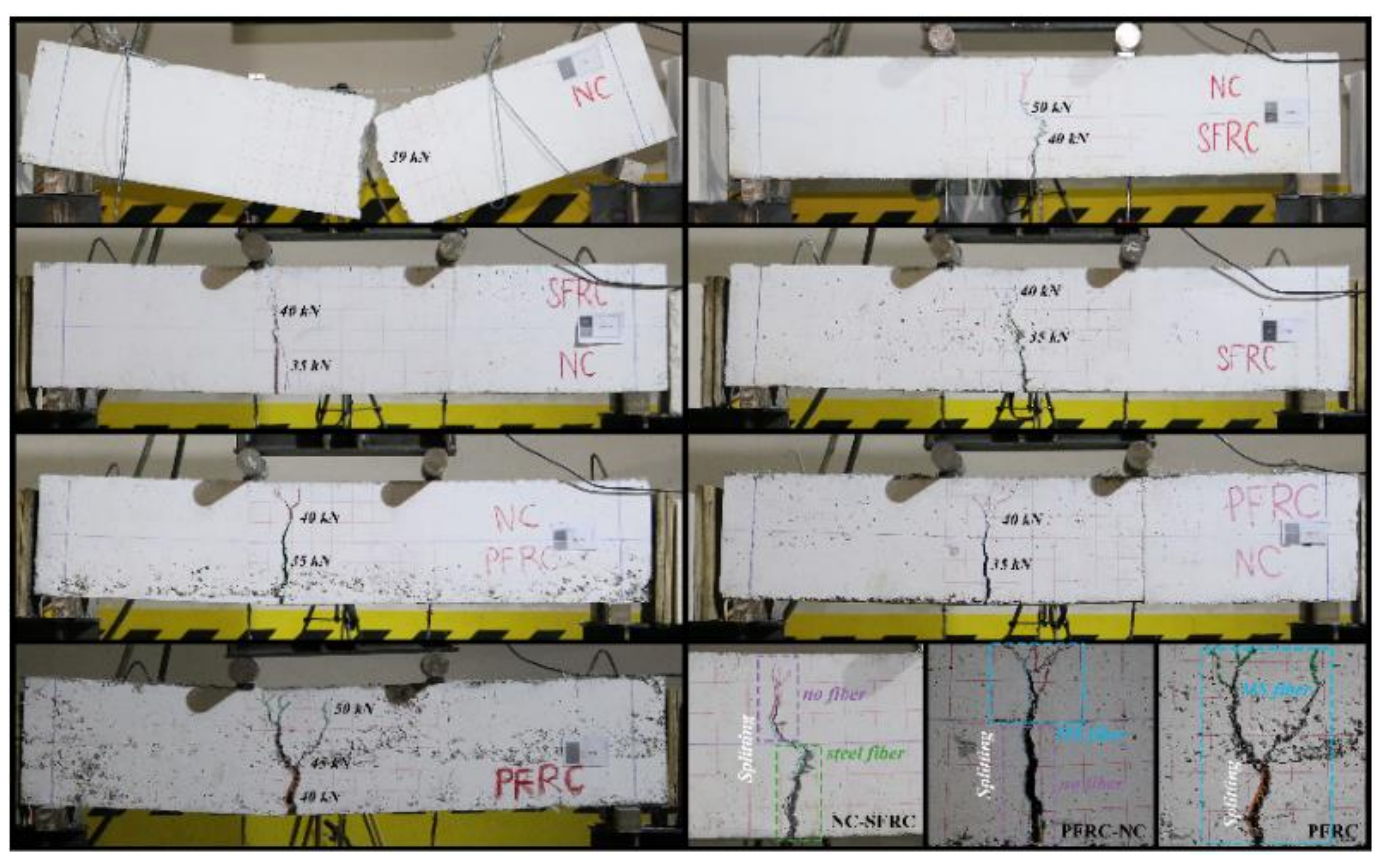

Şekil 7. Kiriş çatlak davranışı

\section{Sonuç}

$\mathrm{Bu}$ çalışmanın temel amacı FRC kirişlerde fiber kullanımını azaltarak, yapı maliyetlerini düşürmek aynı zamanda fiber katkısız kirişe göre daha sünek bir kiriş üretilmesidir. Bu amaçla 2 farklı fiber tipinde (MS ve çelik) ve farklı fiber beton konumlarına göre (üst ve alt) 7 farklı beton kiriş üretilmiştir. Kirişlerin mekanik özelliklerini belirlemek amacıyla küp ve silindir numunelerde basınç ve yarmada çekme dayanımı testleri yapıldı. Eğilme dayanımını görmek amacıyla kirişler üzerinde 4 noktalı eğilme testleri yapılmıştır. Çalışmada yapılan deneyler ve analizler sonrası aşağıdaki sonuçlar çıkartılmıştır.

- PFRC kişinde NC kirişe oranla yük taşıma kapasitesinde $\% 30$ artış görülmüştür. Benzer şekilde NC-SFRC kirişinde de NC kirişe kıyasla yük taşıma kapasitesine \%27 artış görülmüştür. Diğer tüm kirişlerde ise NC kirişe kıyasla yük taşıma kapasitelerinde artış görülmemiştir. FRC katmanının üst kısımda olması durumunda, alt kısımda bulunan NC katmanının erken göçmesi sebebiyle tam performansa ulaşılmadan kırılma gerçekleşmiştir.

- Yük-deplasman davranışları incelendiğine PFRC içeren kirişlerde yük taşıma kapasiteleri maksimuma ulaştıktan sonra yük altında deplasman yapabilme kabiliyeti SFRC içeren kirişlere göre daha fazladır. SFRC içeren kirişlerde maksimum yüke ulaşıldıktan sonra yükün azalan eğilimde olduğu görülmüştür.

- Enerji yutma kapasiteleri incelendiğinde NC-SFRC ve NC-PFRC kirişleri SFRC-NC ve PFRC-NC kirişlerine oranla daha akma sonrası daha sünek davranış yaptığı söylenebilir. NC kirişinde de bilindiği üzere gevrek bir kırılma gerçekleşmiştir.

- Lifli betonun üst kısımda bulunduğu SFRC-NC ve PFRC-NC kirişlerinde makismum yük taşıma kapasitesine ulaşıldıktan sonra ani yük kayıpları görülmüştür. Fakat bu ani yük kaybından sonra kiriş yük altında deplasman yapmaya devam etmektedir. $\mathrm{Bu}$ duruma alt kısımda bulunan $\mathrm{NC}$ katmanının göçmesinden sonra üst kısımda bulunan FRC katmanının yük taşımaya devam etmesi sebep olmaktadır.

- Sonuç olarak betona MS ve çelik fiber ilavesinin yük taşıma kapasitesini ve sünekliliği arttırdığı ve çatlak oluşumu geciktirdiği görülmektedir. FRC betonun alt katmanda kullanılmasının kirişte eğilme dayanımını olumlu yönde etkilediği görülmüştür. Fiber miktarının azaltılmasının fiber kullanımının yaygın olduğu yapı maliyetlerine olumlu yönde katkı sağlanılacağı düşünülmektedir.

\section{Kaynakça}

Abbass, W., Khan, M. I., \& Mourad, S. (2018). Evaluation of mechanical properties of steel fiber reinforced concrete with different strengths of concrete. Construction and Building Materials, $\quad 168, \quad 556-569$. https://doi.org/10.1016/j.conbuildmat.2018.02.164

Altoubat, S., Yazdanbakhsh, A., \& Rieder, K. A. (2009). Shear behavior of macro-synthetic fiber-reinforced concrete beams without stirrups. ACI Materials Journal, 106(4), 381-389. https://doi.org/10.14359/56659

ASTM C 1116. (2015). Standard Specification for FiberReinforced Concrete.

Biolzi, L., \& Cattaneo, S. (2017). Response of steel fiber reinforced high strength concrete beams: Experiments and code predictions. Cement and Concrete Composites, 77, 113. https://doi.org/10.1016/j.cemconcomp.2016.12.002

Bolat, H., Şimşek, O., Çullu, M., Durmuş, G., \& Can, Ö. (2014). The effects of macro synthetic fiber reinforcement use on physical and mechanical properties of concrete. Composites Part B: Engineering, 61, 191-198. https://doi.org/10.1016/j.compositesb.2014.01.043

BS EN 197-1. (2011). Cement Composition, specifications and conformity criteria for common cements.

Buratti, N., Mazzotti, C., \& Savoia, M. (2011). Post-cracking behaviour of steel and macro-synthetic fibre-reinforced 
concretes. Construction and Building Materials, 25(5), 27132722. https://doi.org/10.1016/j.conbuildmat.2010.12.022

Chaboki, H. R., Ghalehnovi, M., Karimipour, A., \& de Brito, J. (2018). Experimental study on the flexural behaviour and ductility ratio of steel fibres coarse recycled aggregate concrete beams. Construction and Building Materials, 186, 400-422. https://doi.org/10.1016/j.conbuildmat.2018.07.132

Chaboki, H. R., Ghalehnovi, M., Karimipour, A., de Brito, J., \& Khatibinia, M. (2019). Shear behaviour of concrete beams with recycled aggregate and steel fibres. Construction and Building Materials, 204, 809-827. https://doi.org/10.1016/j.conbuildmat.2019.01.130

Chiranjeevi Reddy, K., \& Subramaniam, K. V. L. (2017). Analysis for multi-linear stress-crack opening cohesive relationship: Application to macro-synthetic fiber reinforced concrete. Engineering Fracture Mechanics, 169, 128-145. https://doi.org/10.1016/j.engfracmech.2016.11.015

de Alencar Monteiro, V. M., Lima, L. R., \& de Andrade Silva, F. (2018). On the mechanical behavior of polypropylene, steel and hybrid fiber reinforced self-consolidating concrete. Construction and Building Materials, 188, 280-291. https://doi.org/10.1016/j.conbuildmat.2018.08.103

Ding, Y., Liu, G., Hussain, A., Pacheco-Torgal, F., \& Zhang, Y. (2019). Effect of steel fiber and carbon black on the selfsensing ability of concrete cracks under bending. Construction and Building Materials, 207, 630-639. https://doi.org/10.1016/j.conbuildmat.2019.02.160

Hasan, M. J., Afroz, M., \& Mahmud, H. M. I. (2011). An Experimental Investigation on Mechanical Behavior of Macro Synthetic Fiber Reinforced Concrete. Environmental Engineering, 11(03), 18-23.

Hsie, M., Tu, C., \& Song, P. S. (2008). Mechanical properties of polypropylene hybrid fiber-reinforced concrete. Materials Science and Engineering A, 494(1-2), 153-157. https://doi.org/10.1016/j.msea.2008.05.037

Hu, B., \& Wu, Y. F. (2018). Effect of shear span-to-depth ratio on shear strength components of RC beams. Engineering Structures, 168(May), 770-783. https://doi.org/10.1016/j.engstruct.2018.05.017

Hussein, L., \& Amleh, L. (2015). Structural behavior of ultra-high performance fiber reinforced concrete-normal strength concrete or high strength concrete composite members. Construction and Building Materials, 93, 1105-1116. https://doi.org/10.1016/j.conbuildmat.2015.05.030

Issa, M. S., Metwally, I. M., \& Elzeiny, S. M. (2011). Influence of fibers on flexural behavior and ductility of concrete beams reinforced with GFRP rebars. Engineering Structures, 33(5), 1754-1763. https://doi.org/10.1016/j.engstruct.2011.02.014

Kazemi, M. T., Golsorkhtabar, H., Beygi, M. H. A., \& Gholamitabar, M. (2017). Fracture properties of steel fiber reinforced high strength concrete using work of fracture and size effect methods. Construction and Building Materials, 142 , 482-489. https://doi.org/10.1016/j.conbuildmat.2017.03.089

Kazmi, S. M. S., Munir, M. J., Wu, Y. F., \& Patnaikuni, I. (2018). Effect of macro-synthetic fibers on the fracture energy and mechanical behavior of recycled aggregate concrete. Construction and Building Materials, 189, 857-868. https://doi.org/10.1016/j.conbuildmat.2018.08.161

Kazmi, S. M. S., Munir, M. J., Wu, Y. F., Patnaikuni, I., Zhou, Y., \& Xing, F. (2019). Axial stress-strain behavior of macrosynthetic fiber reinforced recycled aggregate concrete. Cement and Concrete Composites, 97(January), 341-356. https://doi.org/10.1016/j.cemconcomp.2019.01.005

Martinola, G., Meda, A., Plizzari, G. A., \& Rinaldi, Z. (2010). Strengthening and repair of $\mathrm{RC}$ beams with fiber reinforced concrete. Cement and Concrete Composites, 32(9), 731-739. https://doi.org/10.1016/j.cemconcomp.2010.07.001

Mudadu, A., Tiberti, G., Germano, F., Plizzari, G. A., \& Morbi, A. (2018). The effect of fiber orientation on the post-cracking behavior of steel fiber reinforced concrete under bending and uniaxial tensile tests. Cement and Concrete Composites, 93(July),

https://doi.org/10.1016/j.cemconcomp.2018.07.012

Nguyen, D. L., Thai, D. K., Nguyen, H. T. T., Nguyen, T. Q., \& Le-Trung, K. (2021). Responses of composite beams with high-performance fiber-reinforced concrete. Construction and Building Materials, 270, 121814. https://doi.org/10.1016/j.conbuildmat.2020.121814

Oh, B. H., Kim, J. C., \& Choi, Y. C. (2007). Fracture behavior of concrete members reinforced with structural synthetic fibers. Engineering Fracture Mechanics, 74(1-2), 243-257. https://doi.org/10.1016/j.engfracmech.2006.01.032

Pujadas, P., Blanco, A., Cavalaro, S., de la Fuente, A., \& Aguado, A. (2017). The need to consider flexural post-cracking creep behavior of macro-synthetic fiber reinforced concrete. Construction and Building Materials, 149, 790-800. https://doi.org/10.1016/j.conbuildmat.2017.05.166

Smarzewski, P., \& Barnat-Hunek, D. (2018). Property Assessment of Hybrid Fiber-Reinforced Ultra-HighPerformance Concrete. International Journal of Civil Engineering, 16(6), 593-606. https://doi.org/10.1007/s40999-017-0145-3

Song, P. S., \& Hwang, S. (2004). Mechanical properties of highstrength steel fiber-reinforced concrete. Construction and Building Materials, 18(9), 669-673. https://doi.org/10.1016/j.conbuildmat.2004.04.027

Sucharda, O., Pajak, M., Ponikiewski, T., \& Konecny, P. (2017). Identification of mechanical and fracture properties of selfcompacting concrete beams with different types of steel fibres using inverse analysis. Construction and Building Materials, 138 , 263-275. https://doi.org/10.1016/j.conbuildmat.2017.01.077

Tong, T., Yuan, S., Wang, J., \& Liu, Z. (2021). The role of bond strength in structural behaviors of UHPC-NC composite beams: Experimental investigation and finite element modeling. Composite Structures, 255(February 2020), 112914. https://doi.org/10.1016/j.compstruct.2020.112914

Yao, W., Li, J., \& Wu, K. (2003). Mechanical properties of hybrid fiber-reinforced concrete at low fiber volume fraction. Cement and Concrete Research, 33(1), 27-30. https://doi.org/10.1016/S0008-8846(02)00913-4

Yin, S., Tuladhar, R., Shi, F., Combe, M., Collister, T., \& Sivakugan, N. (2015). Use of macro plastic fibres in concrete: A review. Construction and Building Materials, 93, 180-188. https://doi.org/10.1016/j.conbuildmat.2015.05.105 